\title{
Effect of post processing on the creep performance of laser powder bed fused Inconel
}

718

\author{
${ }^{\mathrm{a}}$ Z. Xu, ${ }^{\mathrm{a} J . W}$. Murray, ${ }^{\mathrm{a} C . J . ~ H y d e *},{ }^{\mathrm{a}, \mathrm{b}}$ A.T. Clare \\ a Department of M3, Faculty of Engineering, University of Nottingham, University Park, Nottingham, NG7 2RD, UK \\ $\mathrm{b}$ Department of Mechanical, Materials and Manufacturing Engineering, Faculty of Science and Engineering, University of \\ Nottingham China, 199 Taikang East Road, University Park, Ningbo 315100, China \\ *Corresponding author, email: christopher.hyde@nottingham.ac.uk
}

\begin{abstract}
In this study, the creep performance of laser powder bed fusion manufactured Inconel 718 specimens is studied in detail and compared with conventional hot-rolled specimens alongside as-built then heattreated and as-built then hot-isostatic pressed specimens. Hot-rolled specimens showed the best creep resistance, while the hot-isostatic pressed specimens yielded the worst performance, inferior to the asbuilt condition. Creep testing of all samples showed increased secondary creep rate was consistently correlated with a reduced life. Fractography revealed intergranular fracture was the primary failure mode for all as-built samples. Preferential intergranular precipitation in the case of the hot-isostatic pressed specimens during hot-isostatic pressing extensive intergranular cracking as the primary failure mechanism. Heat-treated specimens possessed only sparse intergranular precipitates, thereby explaining an improved creep lifetime. The hot-rolled specimens, having smallest grain size, showed the least extensive cracking, particularly in locations of finest grains, explaining avoidance of intergranular fracture as a key creep mechanism, thereby explaining the ductile creep fracture surfaces in the case of the hot-rolled samples.
\end{abstract}

Keywords: creep; laser powder bed fusion; Inconel 718; heat treatment; hot-isostatic pressing 


\section{Introduction}

Inconel 718 is commonly used for turbine discs in the aerospace sector [1] and represents a significant weight percentage of modern aero-engines [2]. Inconel 718 is comprised primarily of $\gamma, \gamma^{\prime}$ and $\gamma^{\prime \prime}$ phases, among which the $\gamma$ " phases is largely responsible for the strengthening mechanism [3]. Polycrystalline Inconel 718 offers high strength and fatigue resistance up to $650^{\circ} \mathrm{C}$ but beyond this temperature the principle strengthening phase decomposes to the $\delta$ phase $[4,5]$. Creep performance of Inconel 718 is limited by microcrack initiation at grain boundaries, correlated with the presence of the delta phase [6]. Resistance to dislocation motion by the $\gamma$ " phase during creep is thought to play a role in improving creep behaviour [7], however, creep void formation, as a key creep failure mechanism is also correlated with the presence of precipitates [8].

Laser powder bed fusion (LPBF) is a key process in the array of additive manufacturing techniques and can produce parts from Inconel 718, albeit with tensile strength properties which have been measured to be superior and inferior to equivalent manufactured material depending on the specific process [9]. Researchers face a critical challenge in trying to manufacture components through powder bed fusion which exhibit microstructural phenomena consistent with the optimised microstructure described above. As an additive process, the use of LPBF also circumvents difficulties in machining Inconel 718 by conventional means. The poor machinability of Inconel 718 is consistent with its good mechanical properties [10]. LPBF uses a high energy laser beam to fuse typically metal particles into full density parts, layer by layer directly from computer-aided design data [11] [12]. This mechanism means highly complex geometries can be manufactured directly in a single build process. Inconel 718 has been manufactured by LPBF previously and its structure has been investigated by several authors. Jia and $\mathrm{Gu}$ [13] used LPBF to produce 98.4\% density Inconel 718 parts. Amato et al. [14] characterised LPBF Inconel 718 parts, revealing a columnar microstructure developed to the building direction due to the directional heat input and cooling direction associated with the process.

Heat treatment is one of the most commonly used post processing techniques to alter the mechanical properties of structures built by powder bed fabrication. After post-processing with hot isostatic 
pressing (HIP) and annealing, tensile properties comparable to the annealed wrought equivalents were measured. Pröbstle et al. [15] reported that heat treated LPBF manufactured Inconel 718 yielded superior creep performance to cast and wrought equivalents. This was explained by higher volume fraction of strengthening $\gamma^{\prime}$ and $\gamma^{\prime \prime}$ phases. They noted that the highest creep strength was achieved with an absence of the $\delta$ phase. They did not evaluate the creep performance of as-built specimens without heat-treatment, and no fractography was included in this study. It was noted that the LPBF based samples showed no significant difference in creep behaviour with sample orientation. Grain boundary precipitates are known to have a significant influence on creep fracture mechanics of Inconel 718 superalloys [8].Wang et al. [16] post processed as-built LPBF Inconel 718 specimens with a twostep heat treatment which caused grain refinement and precipitation of strengthening particles, yielding improved tensile properties comparable to the wrought equivalents. Zhang et al. [17] compared the effects of two standard heat treatment methods on the microstructure and mechanical properties of asbuilt LPBF manufactured components. The two-step standard heat treatment for wrought Inconel 718 caused the precipitation of fine $\gamma^{\prime}$ and $\gamma^{\prime \prime}$ phase and needle like $\delta$ phase, which led to high strength but poor ductility. Inconel 718 treated by the three-step standard heat treatment for casting materials obtained large grain size and reduced $\delta$ phase, yielding improved ductility. As-built specimens treated by both methods possess tensile properties which are comparable to the wrought equivalents. However, little research has been performed related to the effects of post-processing heat-treatment on the creep performance of LPBF manufactured Ni superalloys. Kuo et al. [18] compared the effects of different post processing strategies on the creep performance of LPBF In718 specimens. In the two-stage heat treatment (solution + ageing) process, a solution temperature higher than the $\delta$ solvus $\left(1045^{\circ} \mathrm{C}\right)$ is preferred since needle-shaped $\delta$ phase is harmful to specimen mechanical properties. The dissolution of the $\delta$ phase permits grain boundary growth and releases $\mathrm{Nb}$ which is also required by strengthening particles, i.e. $\gamma^{\prime}$ and $\gamma^{\prime \prime}$ phases. The authors also proved the HIP process can contribute to even better creep resistance by dissolution of the $\delta$ phase and creation of zig-zag features on grain boundaries. HIP has been shown to be able to remove a variety of processing defects including pores in parts made by additive manufacturing methods of electron beam melting of titanium [19] and LPBF of Inconel 718 
[20]. In the latter study, a pressure of at least $100 \mathrm{MPa}$ and a temperature of $1150^{\circ} \mathrm{C}$ was able to increase density to higher than 99.9\%. Kreitcberg et al. [21] showed that HIP'd LPBF manufactured Inconel 625 boosted both recrystallization and grain growth, and lead to an equiaxed microstructure.

In the authors' previous study [22], to determine the potential use of Inconel 718 manufactured by LPBF as an aerospace material, a fundamental investigation into the creep performance of LPBF manufactured Inconel 718 specimens was performed. Here, its creep behavior in comparison to a conventionally manufactured part, is assessed. Additionally, heat treatment, as well as HIP as likely processing routes for LPBF parts, are also evaluated. With fracture analysis, failure mechanisms of the parts tested are also discussed.

Since a comprehensive process chain for the production of high integrity Inconel 718 parts has yet to be defined this work aims to understand the effects of typical heat treatment schedules upon microstructure and resultant creep performance.

\section{Experimental}

Two-bar specimens (TBS) [23, 24], dimensions shown in Figure 1, were used for creep testing. They are much smaller than the conventional uniaxial specimens. So that the two-bar specimen can be easily machined and provide information on all three creep stages with fewer materials. This is consistent with the authors' previous study in which the creep testing experimental arrangement of LPBF specimens was determined [22]. Figure 2 shows a schematic of the testing strategy for this study. Raw TBS Inconel 718 blocks were manufactured using a Renishaw AM250 LPBF system with Renishaw standard gas atomised Inconel 718 powder, whose elemental composition is listed in Table 1. The building parameters of the raw LPBF blocks are listed in Table 2. 


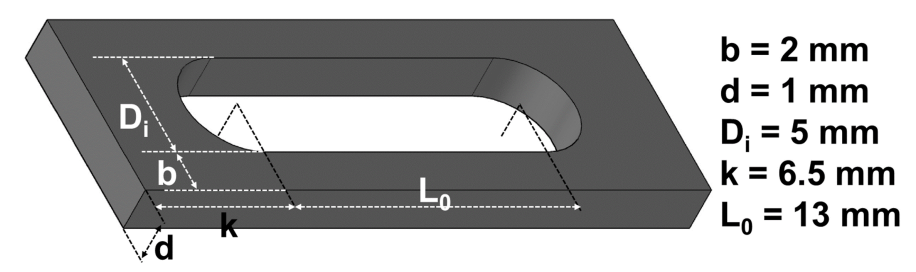

Figure 1 The dimensions of the TBS applied in the creep testing

Table 1 Chemical composition of Renishaw standard gas atomised Inconel 718 powder

\begin{tabular}{cccccccccccccccccccc}
\hline $\mathbf{N i}$ & $\begin{array}{c}\mathbf{C} \\
\mathbf{r}\end{array}$ & $\mathbf{F e}$ & $\mathbf{N b}$ & $\mathbf{M o}$ & $\mathbf{T i}$ & $\begin{array}{c}\mathbf{C} \\
\mathbf{0}\end{array}$ & $\mathbf{A l}$ & $\begin{array}{c}\mathbf{M} \\
\mathbf{n}\end{array}$ & $\mathbf{S i}$ & $\begin{array}{c}\mathbf{C} \\
\mathbf{u}\end{array}$ & $\mathbf{C}$ & $\mathbf{N}$ & $\mathbf{O}$ & $\mathbf{P}$ & $\mathbf{S}$ & $\begin{array}{c}\mathbf{C} \\
\mathbf{a}\end{array}$ & $\begin{array}{c}\mathbf{M} \\
\mathbf{g}\end{array}$ & $\mathbf{S e}$ & $\mathbf{B}$ \\
\hline 50 & 17 & Bal & 4.75 & 2.80 & 0.65 & $\leq$ & 0.20 & $\leq$ & $\leq$ & $\leq$ & 0.02 & $\leq$ & $\leq$ & $\leq 0$ & $\leq 0$ & $\leq$ & $\leq$ & $\leq 0$ & $\leq 0$ \\
$\sim 5$ & $\sim 2$ & anc & $\sim 5.5$ & $\sim 3.3$ & $\sim 1.1$ & 1. & $\sim 0.8$ & 0. & 0. & 0. & $\sim 0.0$ & 0. & 0. & .01 & .01 & 0. & 0. & .00 & .00 \\
5 & 1 & $\mathrm{e}$ & 0 & 0 & 5 & 00 & 0 & 35 & 35 & 30 & 5 & 03 & 03 & 5 & 5 & 01 & 01 & 5 & 5 \\
\hline
\end{tabular}

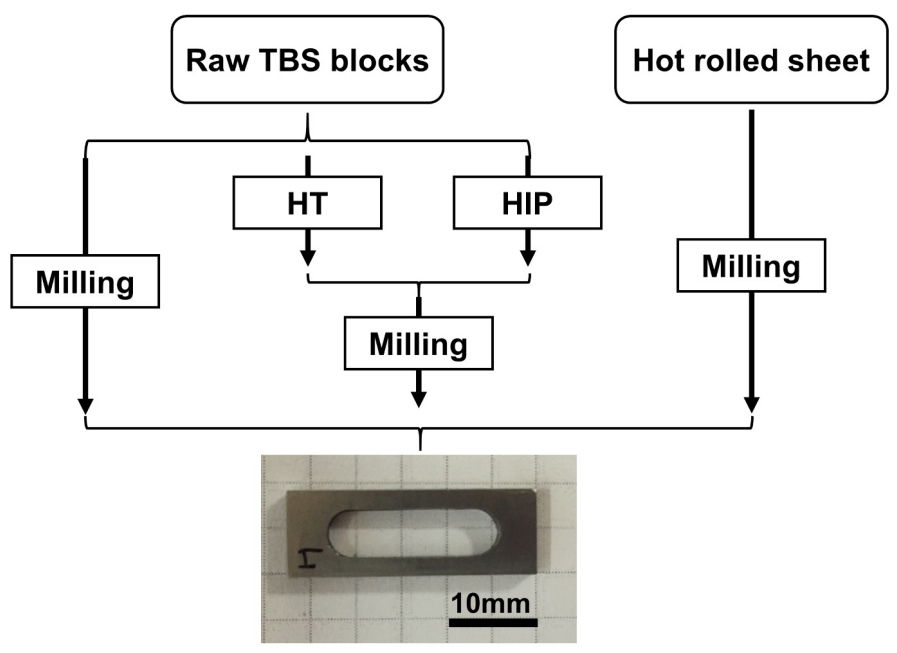

Figure 2 Process methodology prior to creep testing

Table 2 Building parameters for LPBF specimens

\begin{tabular}{ccccc}
\hline Item & $\begin{array}{c}\text { Laser power } \\
(\mathbf{W})\end{array}$ & $\begin{array}{c}\text { Point distance } \\
(\boldsymbol{\mu m})\end{array}$ & $\begin{array}{c}\text { Exposure time } \\
(\boldsymbol{\mu \mathbf { s } )}\end{array}$ & $\begin{array}{c}\text { Hatch distance } \\
(\boldsymbol{\mu \mathbf { m } )})\end{array}$ \\
\hline $\begin{array}{c}\text { Main body } \\
\text { Border }\end{array}$ & 200 & 70 & 70 & 90 \\
\hline
\end{tabular}


Four specimen types were prepared - as-built, hot-rolled, HT and HIP specimens, with five of each specimen type. As-built material was machined directly into TBS oriented in the build direction, by milling. Hot-rolled specimens were cut from a hot-rolled Inconel 718 sheet by water jet then milled. An additional ten, as-built TBS blocks were divided into two groups and subject to HT and HIP separately before milling to the required shape. The standard heat treatment for cast Inconel 718 components (AMS5383 [25]) was used in this study (listed in Table 3). HIP was performed at a pressure of $103 \mathrm{MPa}$ at $1200^{\circ} \mathrm{C}$ for 240 minutes.

Table 3 Heat treatment procedures for casted Inconel 718 components (AMS5383 [25])

\begin{tabular}{cc}
\hline Homogenization & Heat to $1093{ }^{\circ} \mathrm{C} \pm 14$, hold for 1 to $2 \mathrm{~h}$, air cool or faster \\
\hline Solution & Heat to 954 to $982{ }^{\circ} \mathrm{C}$, hold for $>1 \mathrm{~h}$, air cool or faster \\
\hline Ageing & Heat to $718{ }^{\circ} \mathrm{C} \pm 8$, hold for $8 \mathrm{~h}$, furnace cool to $620^{\circ} \mathrm{C} \pm 8$ in $1 \mathrm{~h}$, hold for $10 \mathrm{~h}$, air cool or \\
faster
\end{tabular}

All specimen surfaces were ground and polished to remove the milling affected zone containing any machining defects before testing. Example cross-sections of samples before and after grinding, can be seen in Figure 3 . 

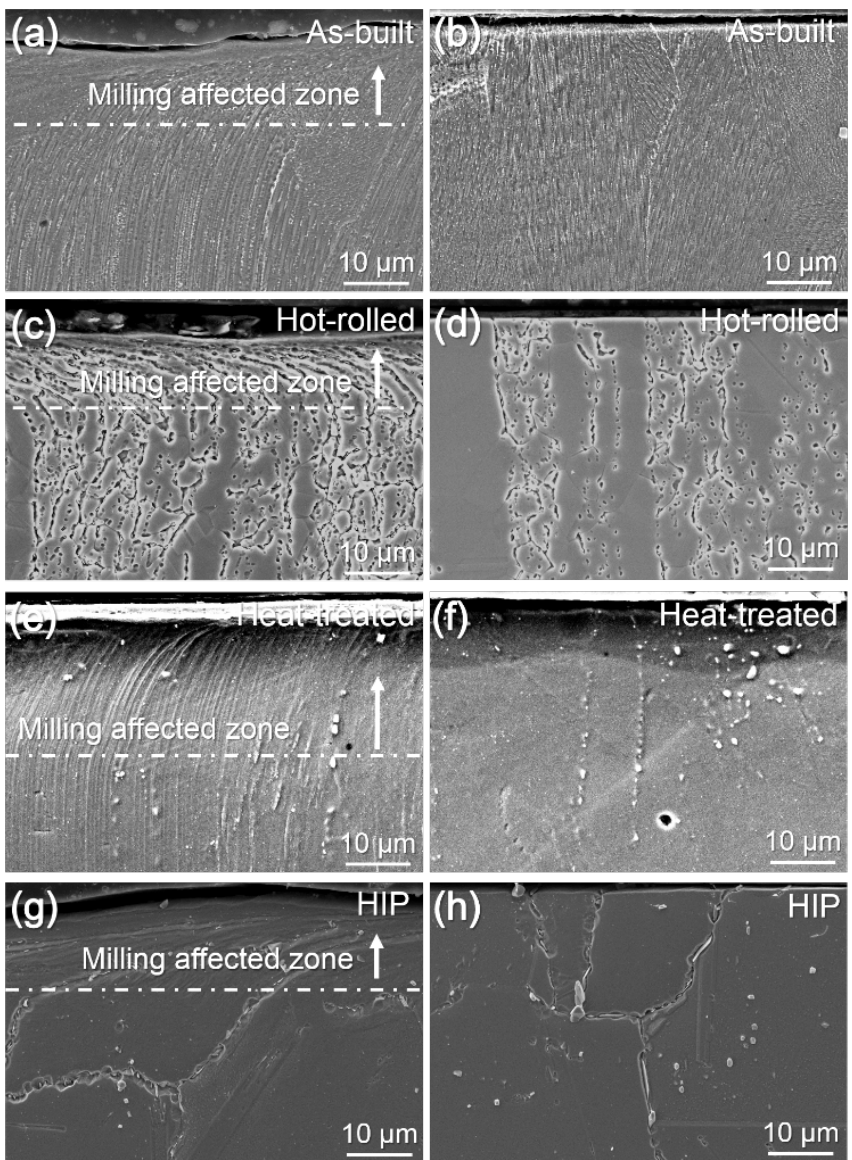

Figure 3 Surface conditions of CNC machined (a) as-built, (c) hot-rolled, (e) HT and (f) HIP TBS specimen, and (b), (d), (f), (h) corresponding samples with milling affected zones removed

An additional two as-built TBS were prepared for tensile testing at room temperature to measure yield strength. Tensile testing was performed at a rate of $0.05 \mathrm{~mm} / \mathrm{s}$. The results are shown in Figure 4 . 


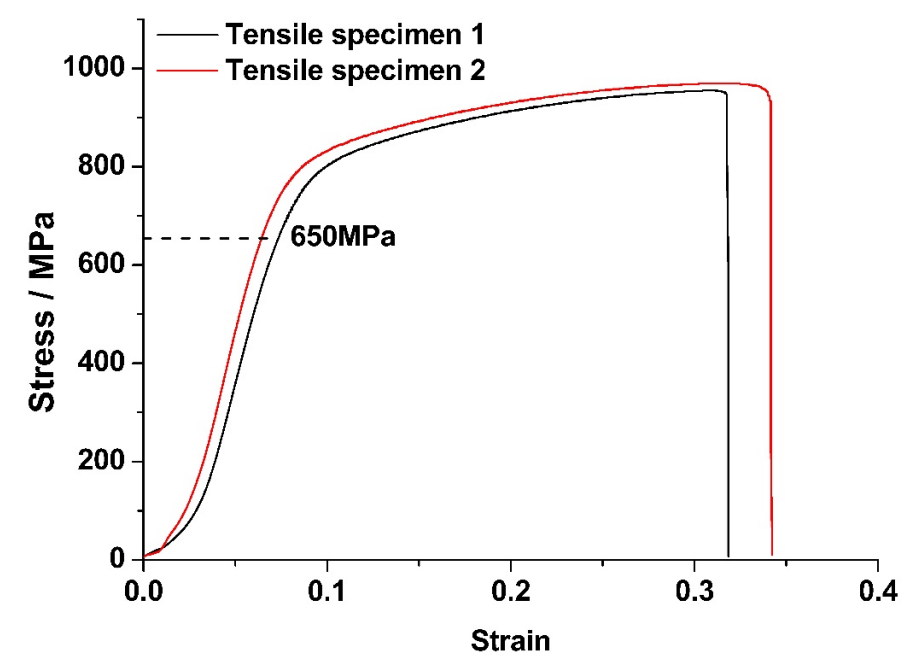

Figure 4 Tensile testing of as-built TBS specimens to verify loading for creep testing

The yield strength of the as-built TBS is approximately $650 \mathrm{MPa}$, with any stress applied higher than this yield stress leading to plastic deformation, causing failure before isolated creep fracture has fully developed. For this reason, creep testing was performed with a stress of $650 \mathrm{MPa}$ to reduce the influence of non-creep induced plastic deformation. The temperature for the testing was $650^{\circ} \mathrm{C}$ which is also the phase transformation temperature for the main strengthening particles, i.e. $\gamma$ ' phase, in Inconel 718 [4], this is also consistent with the previous study [22].

Microstructures of samples were assessed before and after creep testing, using a Nikon ECLIPSE LV100ND Optical Microscope (OM), Hitachi TM3030 scanning electron microscope (SEM) and JEOL 6490LV SEM equipped with energy-dispersive X-ray spectroscopy (EDS). Electrolytic etching solution with $10 \mathrm{ml}$ oxalic acid in $100 \mathrm{ml}$ distilled water at a voltage of $6 \mathrm{~V}$ for $8 \mathrm{~s}$ was used to reveal the microstructure of polished specimens [26]. To evaluate the development of defects and microstructure during creep testing, sections (prepared as shown in Figure 5) near the fracture surfaces were analysed. The first fractured bars were analysed in all cases, for consistency, in the case that the second bar failure did not occur simultaneously with the first bar. 


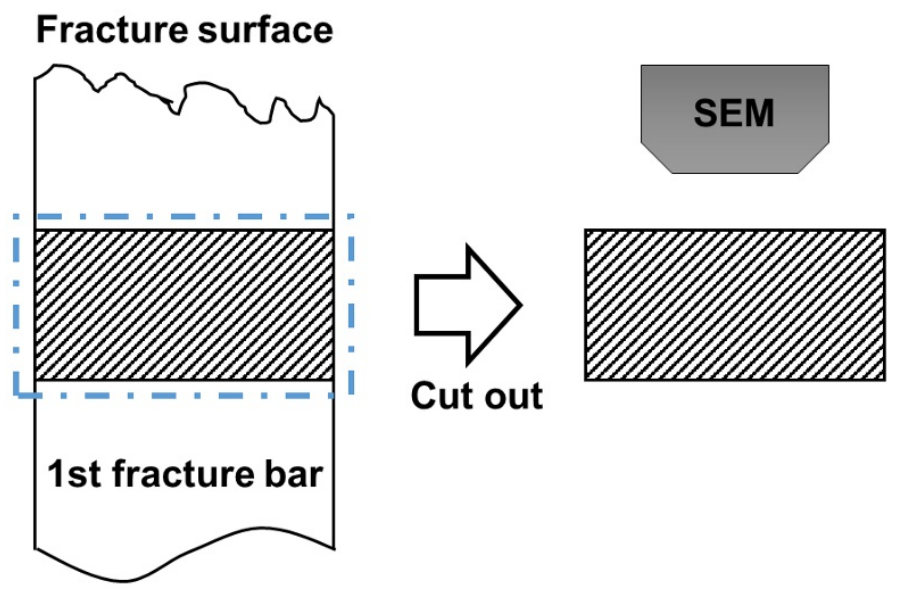

Figure 5 Preparation of sections near fracture surface for microstructural evaluation

\section{Results}

\subsection{Microstructure}

A comparison of the microstructure of as-built, hot-rolled, HT and HIP specimens in three mutually perpendicular planes is shown in Figure 6, comprising secondary electron images of the various planes. The centre legend indicates the orientations of the planes in the TBS. Higher magnification SEM images of the microstructure are shown in Figure 7. 

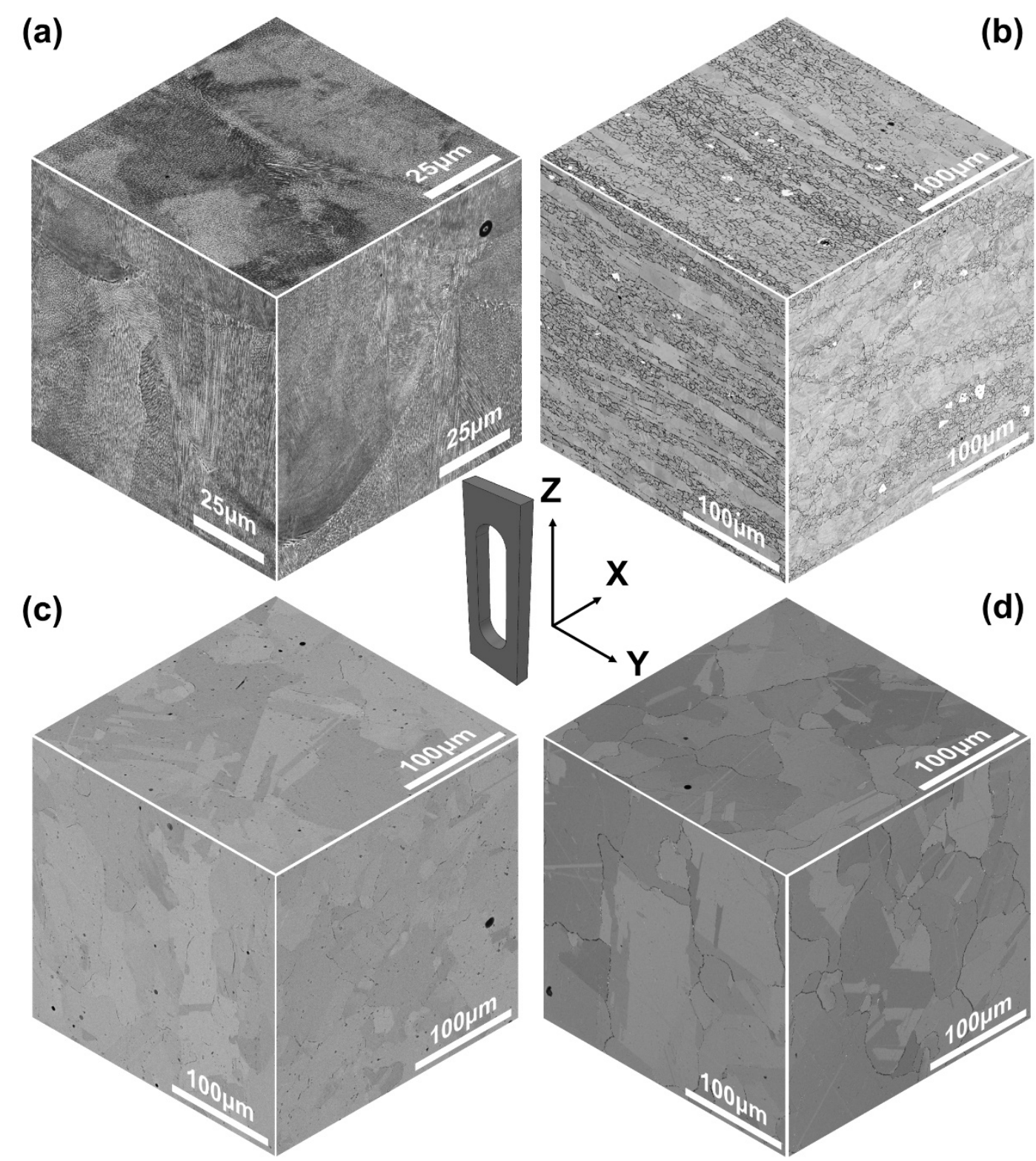

(b)

(d)

Figure 6 Etched microstructure of (a) as-built, (b) hot-rolled, (c) HT and (d) HIP specimens in three mutually perpendicular planes 


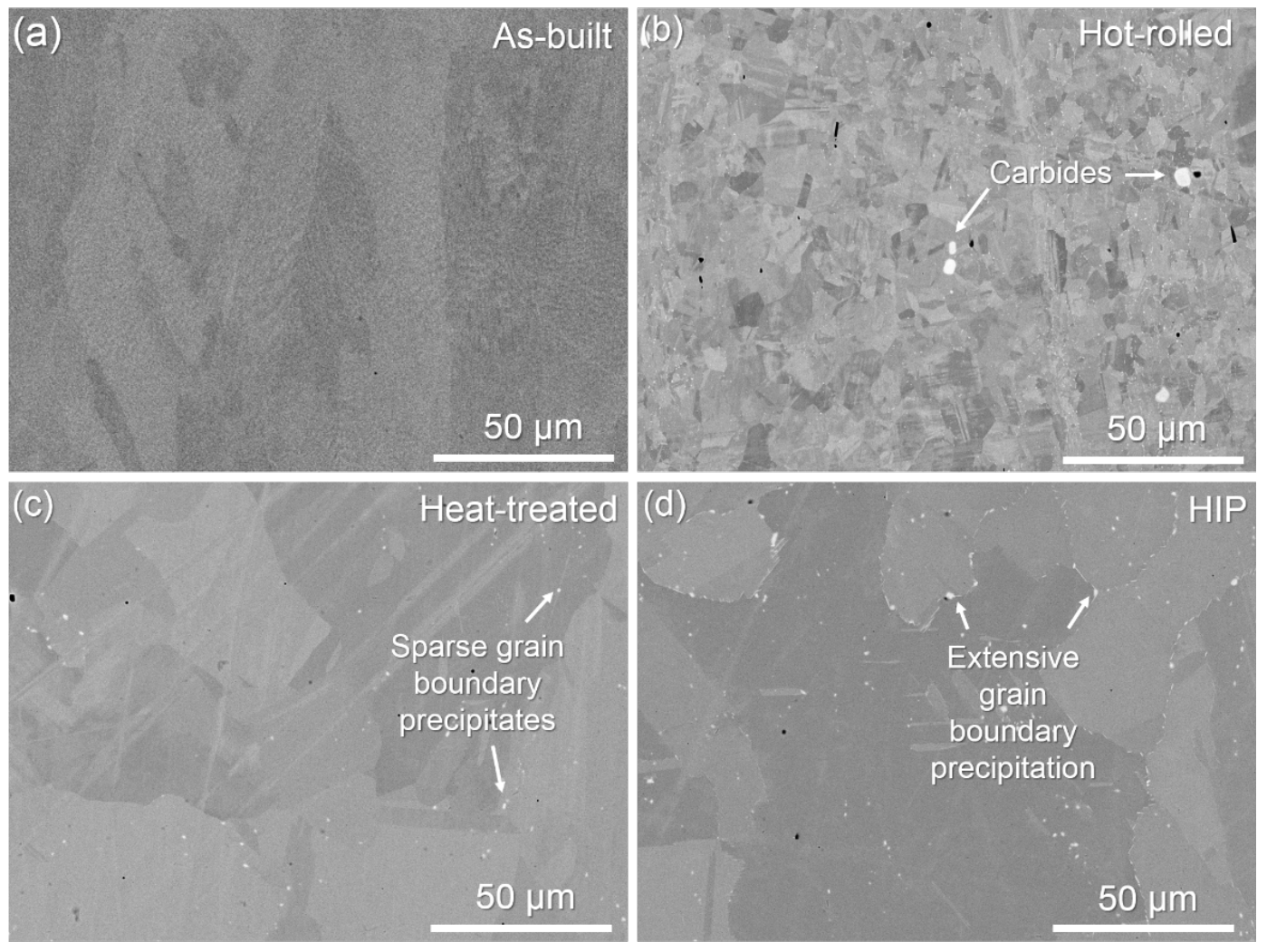

Figure 7 SEM images of unetched samples revealing microstructures in (a) as-built specimen, (b) hot-rolled specimen along with grain boundary precipitates in (c) HT specimen and (d) HIP specimen

In Figure 6, in the hot-rolled specimen, small equiaxed grains located between sections of elongated grains can be seen. A region of equiaxed grains is shown at higher magnification in Figure 7 (b). Blockshaped precipitates, identified as niobium carbide via EDX, with a size of $\sim 10 \mu \mathrm{m}$ are observed mainly in the equiaxed grains zone. The sizes of the grains in the hot-rolled specimens are shown in Figure 8 (b). The as-built specimens show no clear grain shapes, only melt pool shape can be recognised as shown in Figure 8 (a). The as-built specimens (Figure 6 (a) and Figure 7(a)) showed minor microstructural anisotropy. Any anisotropy present in the as-built specimens was mostly eliminated after HT and HIP (as shown in Figure 7 (c) and (d)). The grain sizes of the heat-treated and HIP'd specimens are similar as shown in Figure 8 (c) and (d). Grain boundary precipitates were seen after both HT and HIP. It is clear, based on the un-etched images in Figure 7, that grain boundary precipitation is much more extensive in the case of the HIP'd specimen at the micrometre scale. 

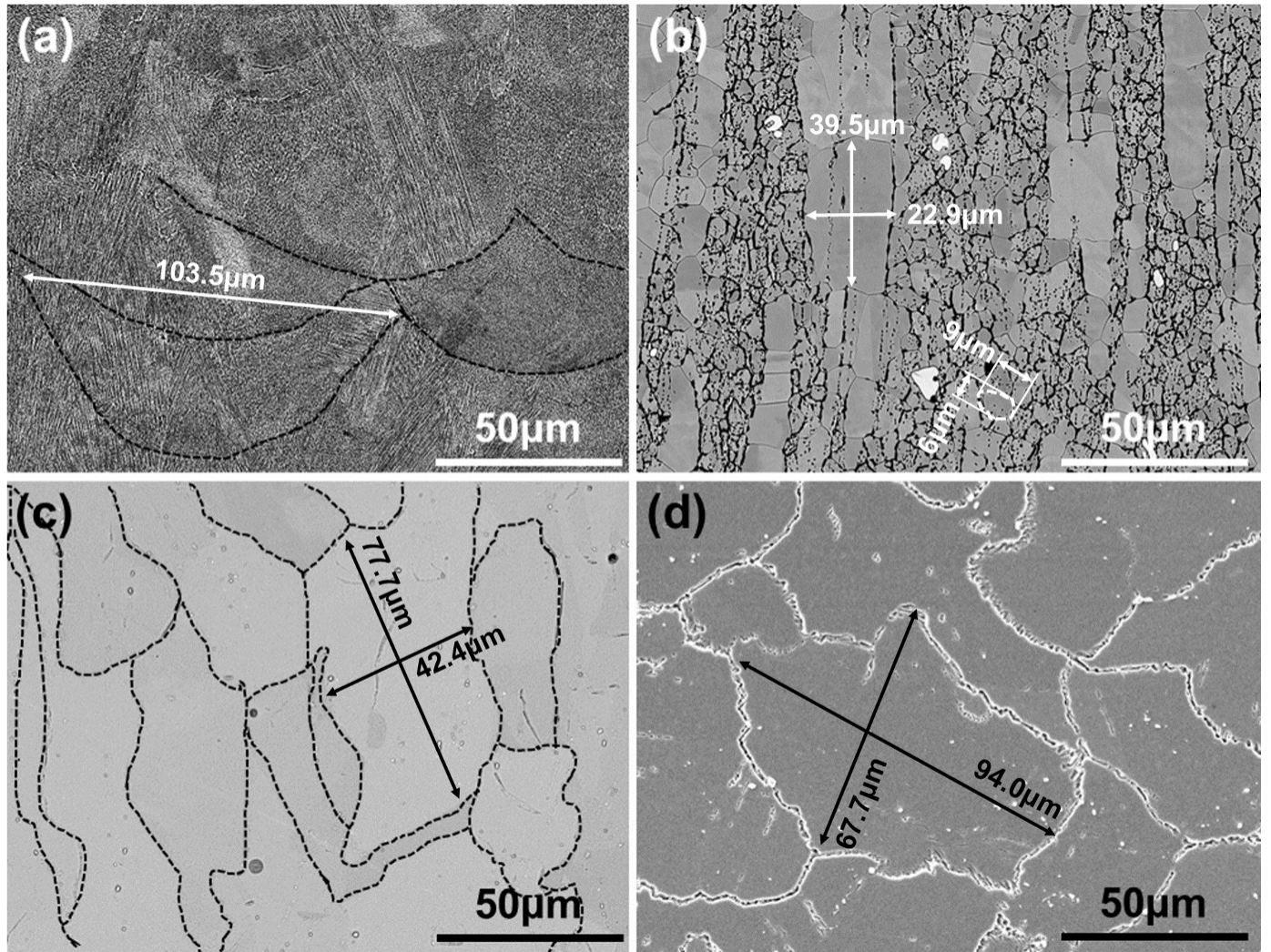

Figure 8 Microstructure and grain (melt pool) size in (a) as-built, (b) hot-rolled, (c) heat treated and (d) HIP'd specimen

\subsection{Creep performance}

Figure 9 shows the lifetime of all creep tested specimens in the format of individual specimen data (Figure 9(a)) as well as mean of all data points with standard error (Figure 9(b)). The hot-rolled specimens yielded a mean lifetime of just under 200 hours, almost four times higher than the as-built specimens which yielded a mean lifetime of 55 hours. Mean lifetime of the HT specimens was 90 hours, and the HIP specimens yielded only 20 hours lifetime. 
(a)

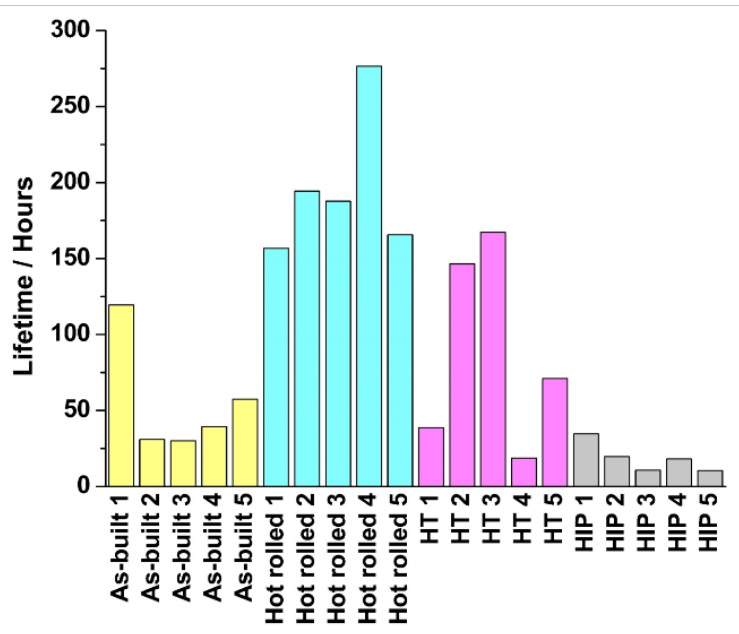

(b)

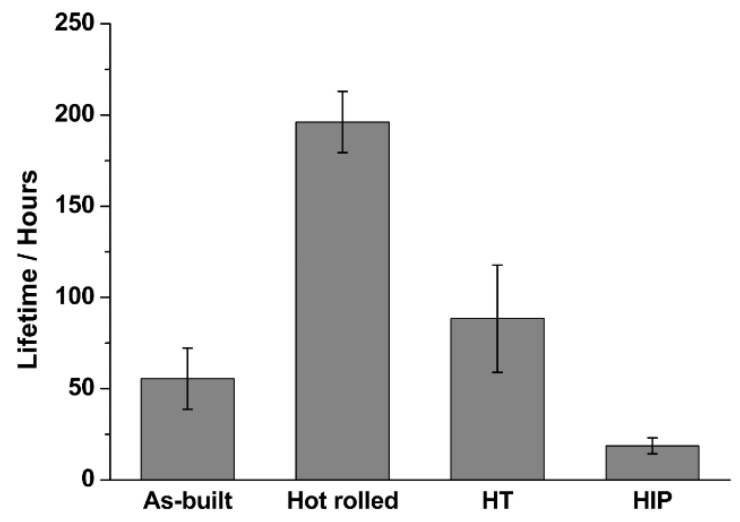

Figure 9 (a) Lifetime of all tested specimens and (b) average lifetime of as-built, hot-rolled, heat-treated and HIP'd specimens

Figure 10 shows the (strain vs. time) creep curves for all tested specimens with Figure 10(b) showing an enlarged view of the short life creep tests highlighted in Figure 10(a). The strain measurements demonstrated here included creep strain, elastic strain and testing error. Steady state creep rates are also shown for individual tests as well as averaged, in Figure 10(c) and (d), respectively. It is clear that higher steady state (secondary) creep rates correspond well to lower overall lifetimes of specimens, and hence secondary creep is likely to be the dominant creep stage determining the overall creep behaviour of the specimens. The hot-rolled specimens yielded the lowest steady creep rate, followed by the HT specimens. It should be noted that the HT specimens yielded a much larger scatter $\left(9.4 \times 10^{-5}\right)$ in creep rate data compared to the hot-rolled specimens $\left(1.3 \times 10^{-5}\right)$. The as-built specimens yielded a much higher steady creep rate compared to the hot-rolled and HT specimens, with a significant scatter in the data. Finally, the HIP specimens produced the highest creep rate, as well as largest scatter in data out of all specimen types. It can be noted that the value of standard error of steady creep rate data is correlated with the steady creep rate itself. As can be seen in Figure 10 (a), the hot-rolled specimens were the only samples to exhibit notable ductile behaviour in the tertiary creep stage. Figure 10 (e) and (f) indicate that the failure mode was much more brittle in the case of the heat-treated and as-built LPBF specimens compared to those of the hot-rolled and HIP'd equivalents. 
(a)

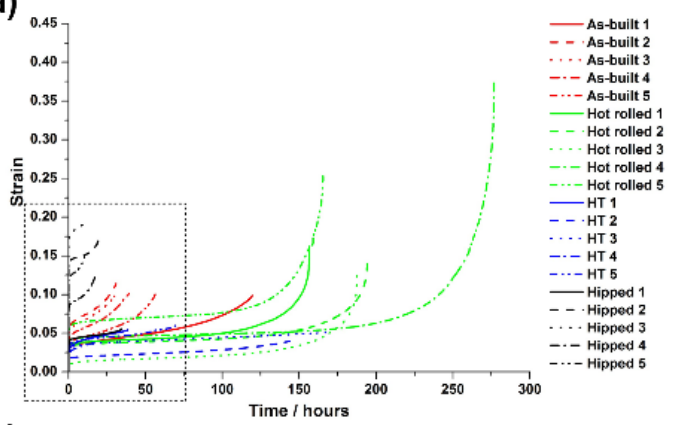

(c)

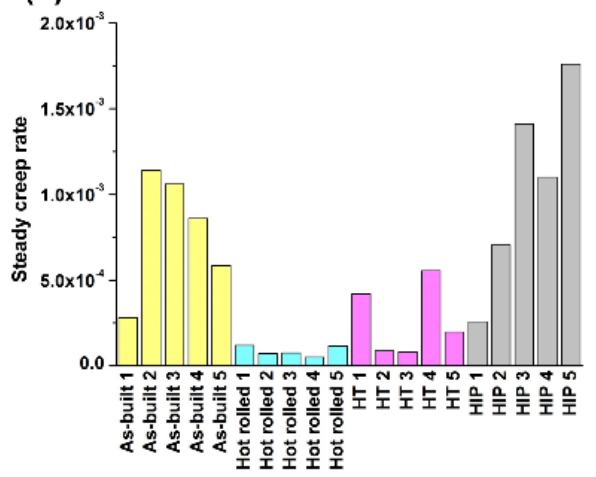

(e)

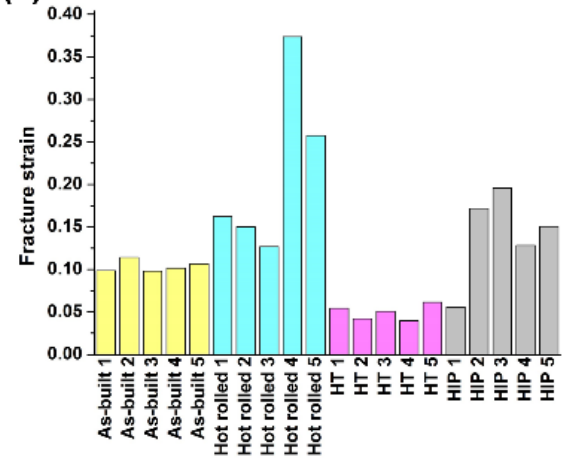

(b)

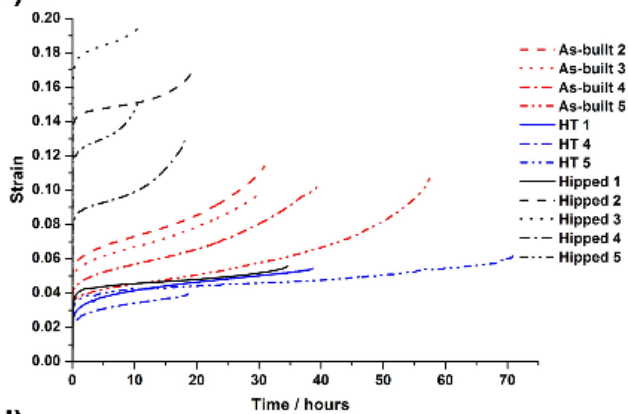

(d)

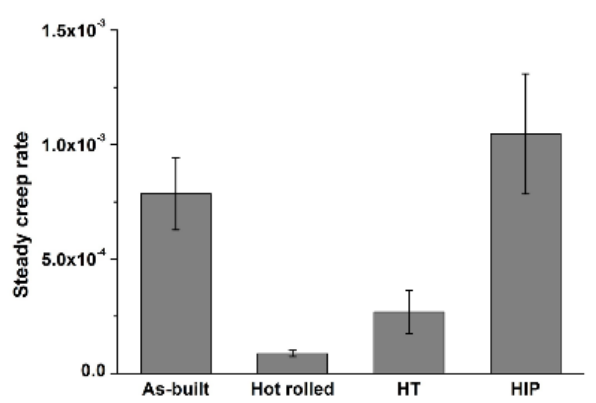

(f)

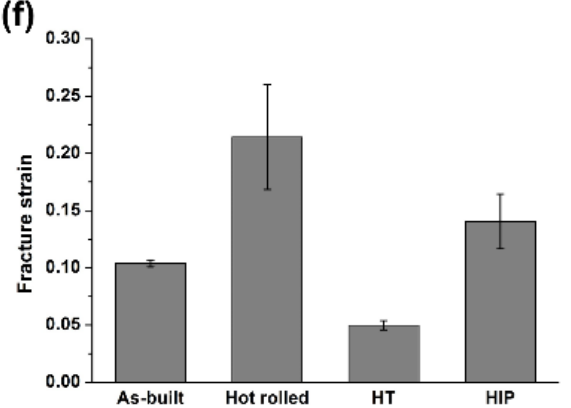

Figure 10 (a) Creep curves of all tested TBS and (b) zoom of region highlighted in (a), (c) steady creep rates of all tests, (d) mean steady creep rates with error bars representing standard errors, (e) fracture strain of all tests and (f) mean fracture strain with error bars representing standard errors

The as-built specimens yielded a larger scatter in results as a percentage of the mean compared to the hot-rolled specimens, with the longest lifetime as-built specimen surviving 120 hours compared to the lowest survival time of 30 hours. This is represented by a standard error of 16.8 hours. The hot-rolled specimens yielded a similar standard error despite their much higher mean lifetime of just under 200 hours. This large standard error for the as-built specimens is reflected in the scatter in steady state creep rates in comparison to those of the hot-rolled specimens. The trend for increased lifetimes was correlated with decreased steady state (secondary) creep rates, with the hot-rolled specimens yielding 
the slowest secondary creep rates. The hot rolled specimens yielded a standard error of $15 \%$ of the mean compared to $20 \%$ in the case of the as-built specimens.

\subsection{Fractography}

Examples of the fracture surfaces of the first fractured bars of the creep tested TBS specimens are shown in Figure 11. Only the first failed bar was analysed here by fractography, given this region of the sample is most representative of the effect of creep damage/failure, whereas the failure of the second bars of the specimens failed in part due to suddenly altered level and location of maximum stress upon the failure of the first, and hence were not considered representative of failure by creep.
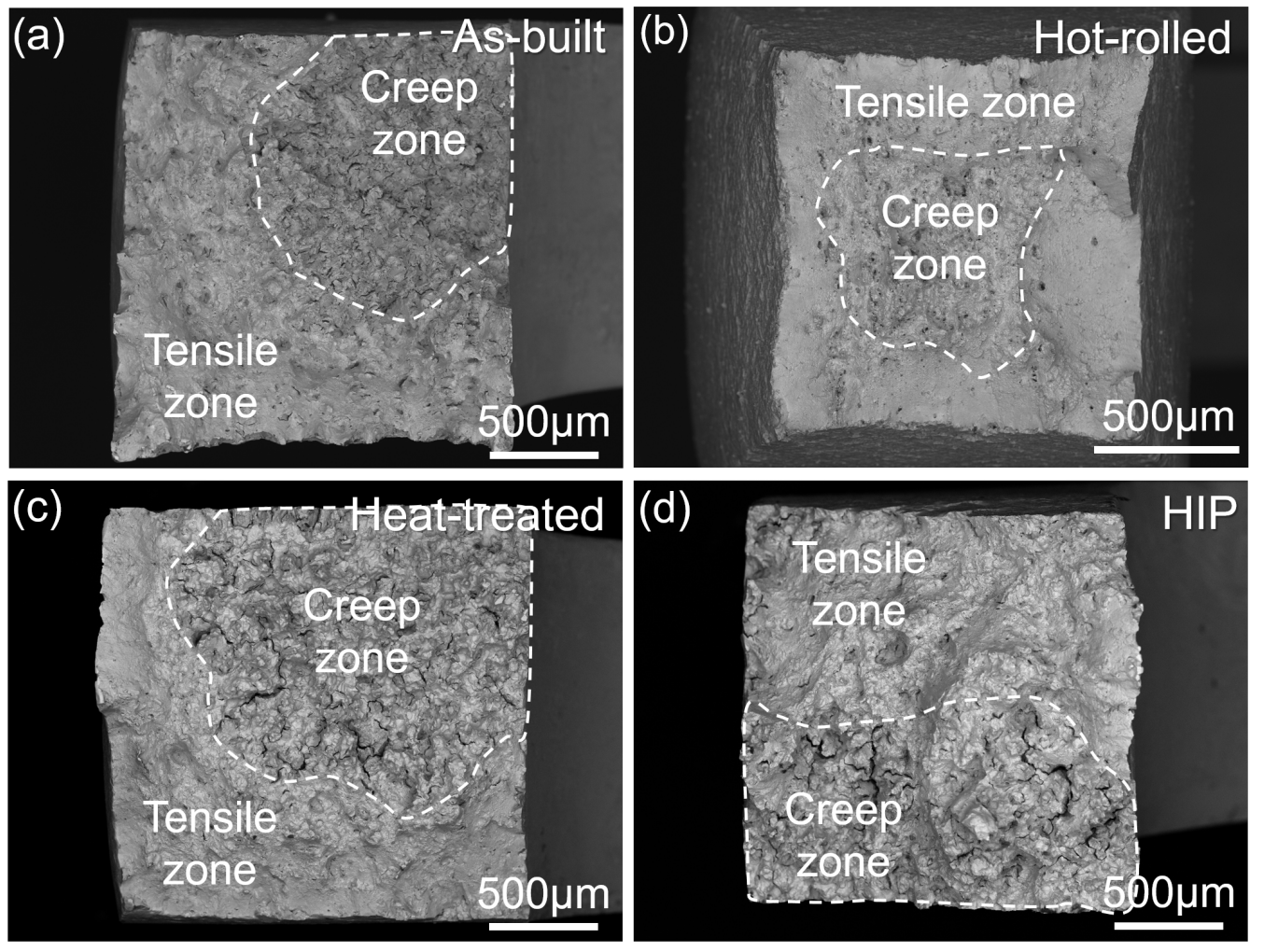

Figure 11 SEM images of fracture surfaces in the 1st fracture bar (a) As-built 1, (b) Hot-rolled 2, (c) HT 4 and (d)

HIP 5 showing a marked difference between crept areas and tensile zones

The fracture surface can be categorised into two zones explained in the authors' previous study [22].

These comprise creep dominated fracture zones and a tensile zone mainly fractured by final ductile tearing. In the three LPBF based specimens, the creep zones represent a similar cross-sectional area.

Whereas the region identified as representative of creep failure in the hot-rolled sample is a smaller 
region and appears to have originated in the centre of the sample. The fracture surfaces identified are reasonably representative of all samples within each sample batch. Higher magnification SEM images of the creep dominated fracture zones on all specimens from Figure 9 are shown in Figure 12.
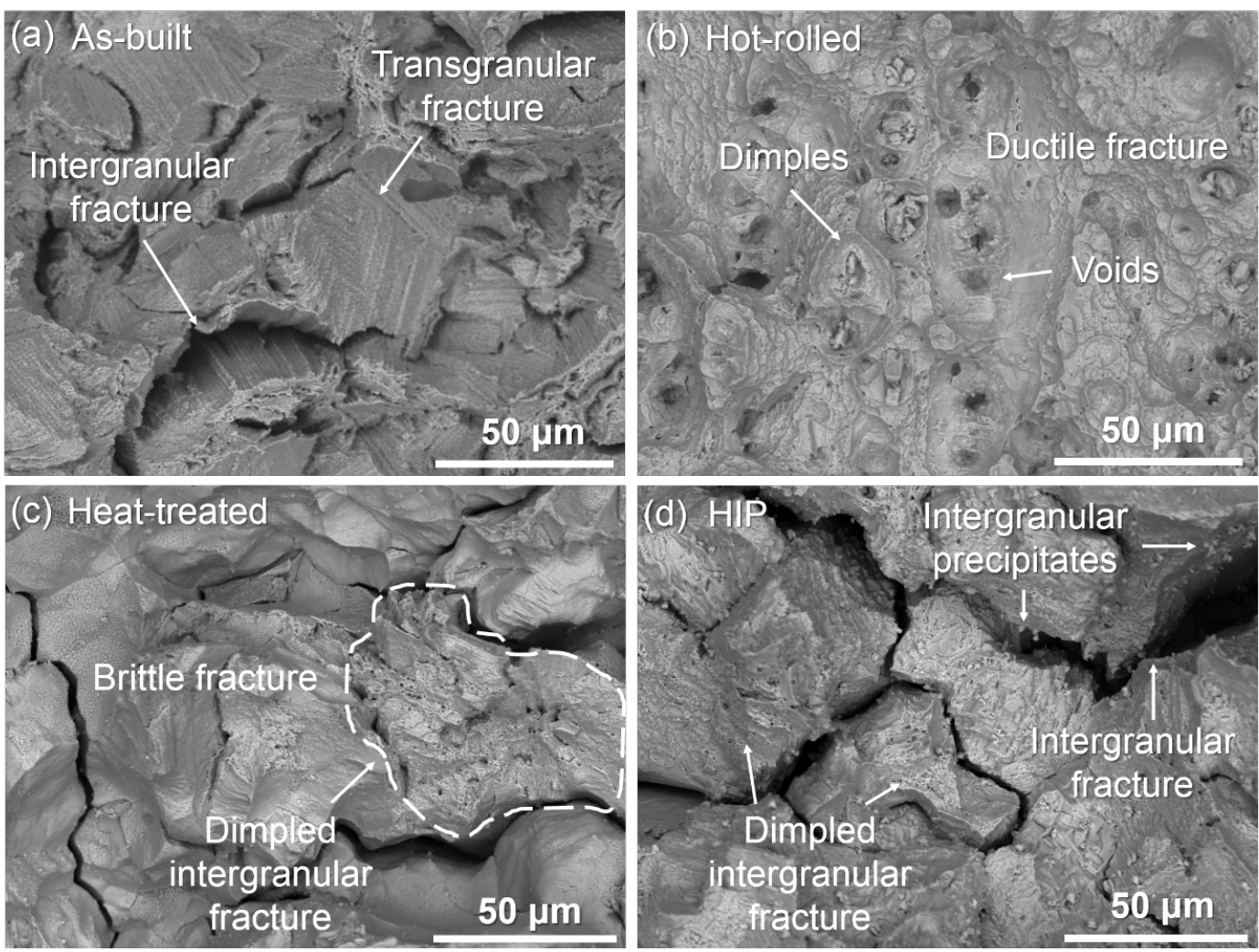

Figure 12 Exemplar fracture surface of the four sample types all captured within respective creep regions

In the fracture surface of the as-built specimen, tear ridges and cracks dominate the creep fracture zone as shown in Figure 12 (a). A crystallographic faceted texture can be seen due to the distinct orientation of cleavage planes, indicative of transgranular fracture [27, 28]. In the case of the hot-rolled specimen, a dimple fracture dominated surface can be seen, indicative of more ductile fracture [27].

The heat-treated sample exhibited a mostly brittle fracture surface, with no cleavage planes visible as is the case in the as-built specimen, however sharp cracks are present indicative of intergranular fracture [27]. A semi-ductile fracture surface can also be identified on some grains on the fracture surface of the heat-treated specimen, with some regions of voids observable on grain surfaces. These regions may be identifiable as quasi-cleavage surfaces, and arise from the growth and coalescence of voids that initiate at and extend along slip band intersections [29]. The HIP'd sample also exhibited intergranular cracking, 
but with the majority of grains exhibiting some evidence of semi-ductile fracture. It can also be noted that precipitates standing proud of the fracture surfaces are also present, giving evidence that the majority of fracture in the case of the HIP specimen is intergranular in nature.

Figure 13 shows SEM images of the tensile fracture zones on the 1st fracture bars of all crept specimens. Interestingly, the as-built specimen exhibited a distinct tensile fracture surface from the heat-treated and HIP'd samples, with evidence of trans-granular and some ductile/dimpled fracture. This contrasts with the heat-treated and HIP'd samples which exhibit a dimpled fracture surface indicative of ductile fracture. The hot-rolled surface however exhibited a more homogeneous ductile fracture surface with no evidence of grain-based fracture. Some voids can be seen in the hot-rolled tensile fracture surface but to a lesser extent than the heat-treated and HIP'd samples.
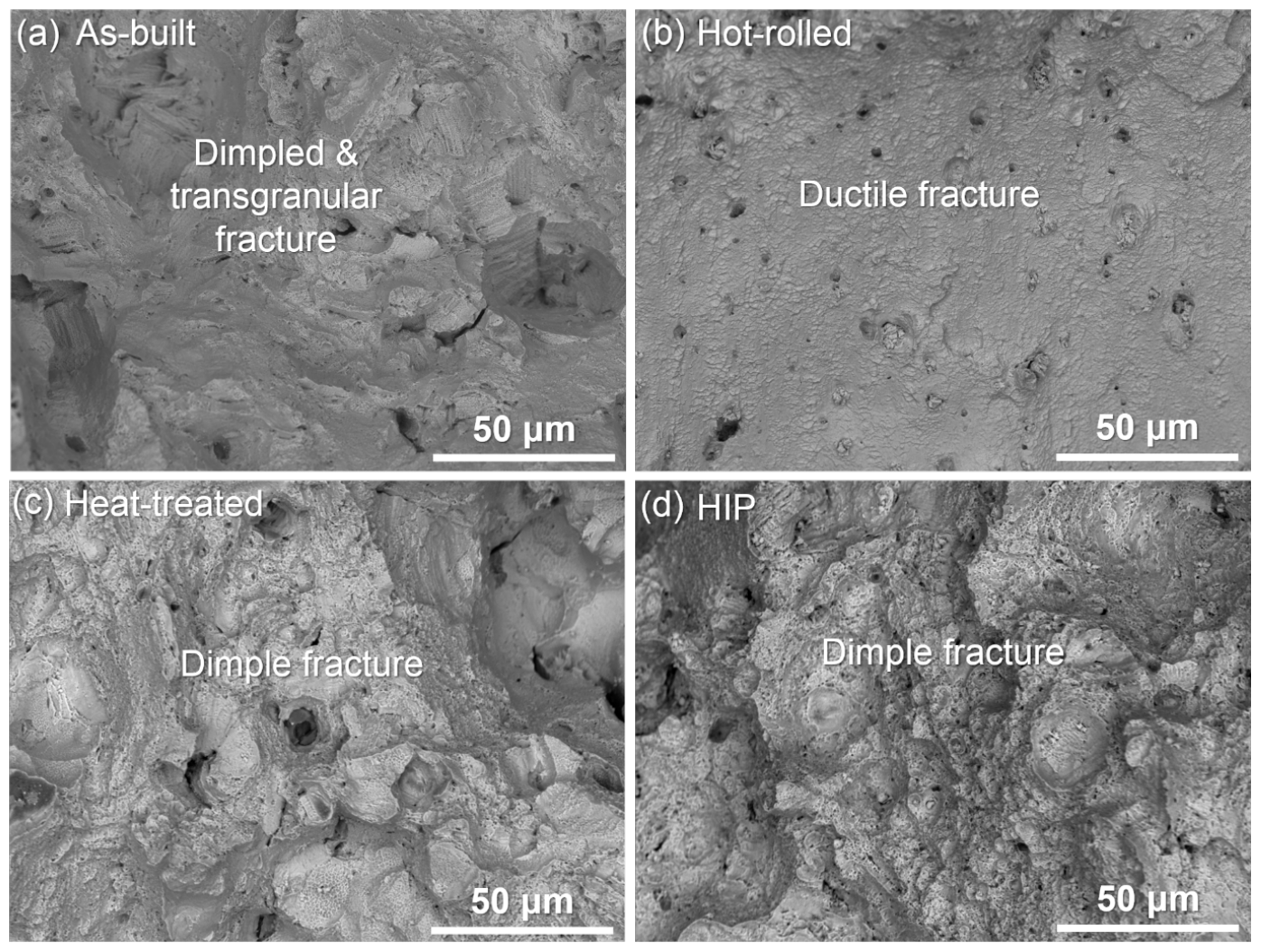

Figure 13 SEM images of tensile fracture zones on crept specimens

\subsection{Crept sample cross-sections}

Figure 14 shows cross-sectional images of the crept specimens near to the fracture surfaces. 

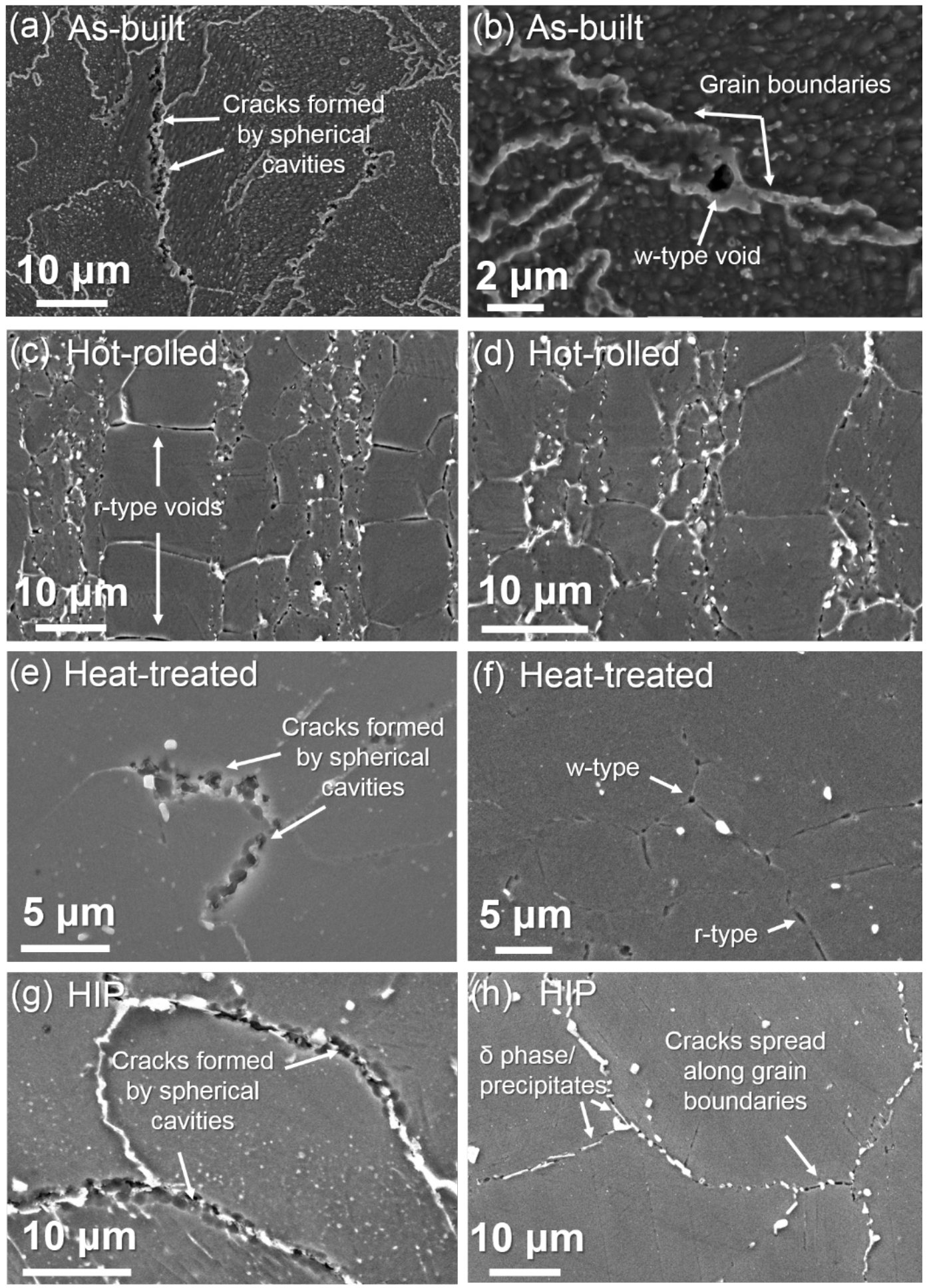

Figure 14 SEM images of etched crept specimens revealing voids and cracks spread along grain boundaries in (a) (b) As-built, (c)\&(d) hot-rolled, (e)\& (f) heat-treated and (g)\&(h) HIP'd specimens

The as-built, heat-treated and HIP'd specimens all exhibited significant intergranular cracking, along with w-type and r-type voids being the precursors. In the hot-rolled specimen, significant intergranular 
voids could be seen appearing to originate as r-type voids. Cracking and/or voids are also generally not present where intergranular precipitates are located in the hot-rolled sample.

The large amount of grain boundaries in the equiaxed grain zone are likely to become failure initiation sites. However, a large amount of needle-shaped, likely $\delta$ phase [30] was also observed on grain boundaries in the hot-rolled specimen. Many r-type voids were observed at the grain boundaries in the case of the hot-rolled specimen, while the LPBF based specimens contain a larger number of w-type voids at grain boundary triple points. The HIP'd specimens contained more precipitates on grain boundaries compared to the HT equivalent. Many fine precipitates, which may be $\delta$ phases, can also be seen at grain boundaries in the HIP'd specimen.

\section{Discussion}

Hot-rolled Inconel 718 yielded consistently superior creep lifetimes to LPBF manufactured and heattreated and HIP'd LPBF Inconel 718. The HIP'd samples performed worse when compared to all other sample types. The trend of increased creep lifetimes was strongly correlated with lower steady state (secondary) creep rates, with the hot-rolled specimens yielding the lowest secondary creep rates. However, it is also clear that the tertiary (i.e. failure) stage of the hot-rolled specimens was much more ductile and longer in duration than for other specimen types.

To explain the difference in steady state creep behaviour between the samples, we can consider first the fracture surfaces in the "creep zone" and "tensile zone" of the first bars to break in the crept specimens. It is clear based on the SEM images of the creep zones in Figure 12, which fracture, mostly intergranular, is the dominant creep failure mechanism seen in the three LPBF manufactured samples. This contrasts with the distinctly dimpled/ductile creep failure mechanism of the hot-rolled sample. Intergranular fracture entirely dominates the heat-treated and HIP'd sample fracture surfaces. In the case of the asbuilt specimen, a transgranular fracture mechanism is also evident. Based on this, it is thought that intergranular fracture is the dominant mechanism causing reduced steady state creep life and ultimately lower creep lifetimes of LPBF based samples. 
To explain the prevalence of cracking during creep in the LPBF samples, and ultimately why the HIP'd specimens performed worse than all other sample types, both the presence of intergranular phases and overall grain size can be considered.

The worst performing sample set, in both creep lifetime and highest steady state creep rate was the HIP'd sample. It is clear based on cross-sectional imaging of the crept sample in a region near to the fracture zone (Figure $14(\mathrm{~g})$ and $(\mathrm{h})$ ), that significant intergranular precipitation takes place during HIPing. It is now thought that intergranular precipitation takes place during creep testing at $650^{\circ} \mathrm{C}$, given this temperature is lower than all phase transformation and solid solution temperatures for candidate phases in Inconel 718 [3]. It is known that preferential nucleation and growth of precipitates or segregation of elements at grain boundaries can exacerbate intergranular cracking [27]. This may be caused by preferential void nucleation/coalescence in these regions, or decohesion between contiguous grains by minor/precipitate phases. It has been shown for Inconel 718 that the presence of $\delta$ precipitates at grain boundaries results in formation of creep voids under creep conditions of $795 \mathrm{MPa}$ and $625^{\circ} \mathrm{C}$, ultimately leading to more severe crack formation and fracture of the material [8]. Propagation of wedge cracks at triple points explains fracture under a relatively low density of $\delta$ precipitates, whereas at higher densities, cavity growth along with grain boundary sliding explains material fracture [8]. The authors also [8] observed that in Inconel 718 at low densities of $\delta$ precipitates, fracture is caused by propagation of wedge cracks initiated at triple points of grain boundaries. In the cross-sectional images in Figure 14, in the heat-treated crept cross-section, cracking at grain boundaries comprising spherical cavities can be seen. This is a well understood mechanism of creep fracture, whereby wedge (w-type) cracks are developed due to an accumulation of spherical cavities, which may be nucleated as a result of grain boundary sliding [31]. Additionally, wedge type voids can be seen at triple junctions in the cross-section of the heat-treated sample. It can also be seen that in the SEM images in Figure 14 that in the HIP sample significant spherical cavity formation occurred. This may be explained by the accumulation of r-type voids or expansion of w-type voids into large intergranular cracks. Based on these mechanisms, the reduction in extent of grain boundary precipitates in the case of the heat-treated sample may explain its improved creep resistance compared to the HIP'd sample. 
In the case of the hot-rolled specimens, the equivalent cross-sectional images in Figure 14 reveal intergranular cracking/grain boundary void formation most prevalent where grains are largest. In regions of equiaxed, smaller grains, cracking is less prevalent. Although it is known that grain boundary diffusion as a creep mechanism is enhanced with a smaller grain size, a fine grain structure can also inhibit intergranular fracture as a mechanism [27]. This may therefore explain why the creep failure zone of the hot-rolled sample is characterised by voids and dimples and a generally ductile failure mode as opposed to an intergranular fracture based surface. It has been shown for example in Ni-base superalloy Udimet 520 that creep crack growth rates were 2.5 times lower in the small grain size variant compared to those of medium and large grain size [32]. Chaturvedi \& Han [33] also investigated the effect of Inconel 718 grain size on its steady state creep rate, and observed that the trend with grain size is variable and highly dependent on testing conditions, namely applied stress and testing temperature.

The precipitates appearing near the crack initiation sites are shown in Figure 15. EDS results of the marked precipitates are given. By checking the elemental distribution and particle morphology, the precipitates were categorised. In the as-built specimen, the spherical cavities appeared mainly on grain boundaries. In the as-built specimen, features at grain boundaries showed no difference in composition compared to the matrix. The authors believe these features may not necessarily be a different phase, but possibly an artefact of etching, given their appearance on all grain boundaries, however it is not possible to be certain. In the hot-rolled specimen, small $\delta$ particles $(3,4,5)$ were found pinned in the grain boundaries of a small equiaxed grain zone which likely performs as a crack initiator. There also exist smaller $\delta$ particles in the grains which have no direction in relation to the cracks. $(\mathrm{Nb}, \mathrm{Ti}) \mathrm{C}$ carbides $(6,7,8)$ are dominant in the heat treated specimen. The carbide (8) precipitated on grain boundaries are expected to act as a crack initiation site. Particle 9 which is slightly rich in $\mathrm{Nb}$ is thought to be the $\delta$ phase [34]. The $\delta$ phases $(10,12,13)$ in the HIP'd specimens possess two types of morphology which are similar to the results obtained by Azadian [35]. Both types are expected to act as crack initiators. However, in the study by Cao [36], a serrated $\delta$ phase, similar to the shape marked by point 12 can 
retard intergranular cracking. Given no cracking or voids were seen near to carbides which precipitated in the grains, these may have no effect on the fracture mechanism under the parameters in this study.
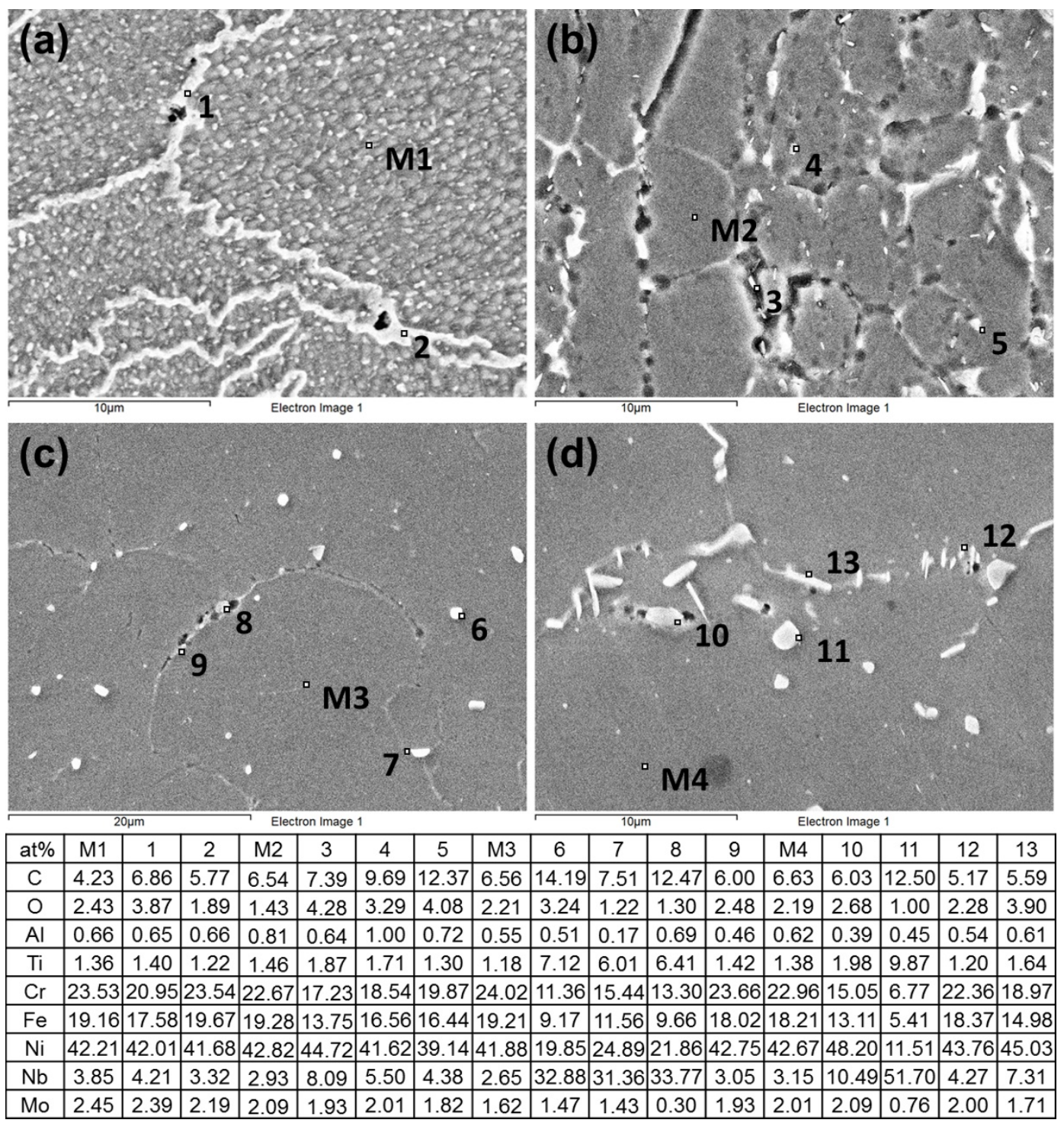

Figure 15 EDS analysis (at\%) of precipitates in (a) as-built, (b) hot rolled, (c) heat treated and (d) HIP'd specimens,

\section{M1-M4 indicate the matrix of the four specimens}

It should be noted that here, a contrasting result to that seen by Probstle was found, whereby heat-treated selective laser melted (SLM, analagous to LPBF) specimens yielded superior creep strength to a cast and wrought sample [15]. This result was explained by the higher level of $\gamma^{\prime} / \gamma$ " phase formation in the case of the SLM material, caused by the absence of the $\delta$ phase, and hence higher availability of $\mathrm{Nb}$ for $\gamma^{\prime} / \gamma^{\prime \prime}$ formation. However, significant grain boundary precipitates were seen in the case of the cast and 
wrought sample, and a fine sub-grain structure was seen in the case of the SLM produced sample, both of which may explain why creep failure occurred more readily in the cast and wrought sample, based on the mechanisms previously discussed.

\section{Conclusions}

- Hot-rolled specimens yielded superior creep lifetimes to LPBF, as well as LPBF then heattreated and LPBF then HIP'd specimens, at conditions of $650 \mathrm{MPa}$ and $650^{\circ} \mathrm{C}$. HIP'd specimens yielded a mean of 20 hours compared to 200 hours for the hot-rolled specimens tested under the same conditions. Heat-treated specimens yielded a mean lifetime of 90 hours, and As-built specimens yielded only 55 hours. Steady state creep rates of all specimens reflected the trends in overall specimen lifetime.

- Excessive intergranular precipitation caused by the HIP process at $1200^{\circ} \mathrm{C}$ explained enhanced intergranular cracking under creep conditions, explaining the worst performance of the HIP'd samples. Heat-treated samples contained a much lower density of intergranular precipitates, thought to reduce the extent of intergranular cracking.

- As-built specimens showed no evidence of intergranular precipitation and hence this explained a transgranular precipitation mode contributing to creep deformation and failure.

- The finer average grain size in the hot-rolled specimens, despite presence of some precipitate phases between grains, is thought to explain the resistance to fracture under creep conditions, hence explaining a dimpled/ductile fracture surface. In regions of finest grain size on the hotrolled specimens, cracking was seen to be reduced in cross-sectional crept samples.

\section{Acknowledgements}

The authors would like to acknowledge the support from Engineering and Physical Sciences Research Council (EPSRC Grants EP/L017121/1). In addition, the authors would like to thank Alexander Jackson-Crisp for his invaluable technical contributions in machining specimens and Shane Maskill for facilitating the creep testing. Authors would also like to thank the Nanoscale and Microscale Research Centre at the University of Nottingham for their assistance with the microscopy presented. 


\section{Data Availability}

The raw/processed data required to reproduce these findings cannot be shared at this time as the data also forms part of an ongoing study

\section{References}

[1] C. Mercer, A.B.O. Soboyejo, W.O. Soboyejo, Micromechanisms of fatigue crack growth in a single crystal Inconel 718 nickel-based superalloy, Acta Materialia 47(9) (1999) 2727-2740.

[2] R.E. Schafrik, D.D. Ward, J.R. Groh, Application of Alloy 718 in GE Aircraft Engines: Past, Present and Next Five Years in: E.A. Loria (Ed.) Superalloys 718, 625, 706 and Various Derivatives TMS, Warrendale, PA, 2001, pp. 1-11.

[3] B. Geddes, H. Leon, X. Huang, Superalloys: Alloying and Performance, ASM International2010.

[4] S.F. Diltemiz, S. Zhang, Superalloys for super jobs, in: S. Zhang, D. Zhao (Eds.), Aerospace Material Handbook, CRC Press, London, 2013, pp. 1-76.

[5] M. Sundararaman, P. Mukhopadhyay, S. Banerjee, Precipitation of the $\delta-N i 3 N b$ phase in two nickel base superalloys, Metallurgical Transactions A 19(3) (1988) 453-465.

[6] T. Ni, J. Dong, Creep behaviors and mechanisms of Inconel718 and Allvac718plus, Materials Science and Engineering: A 700 (2017) 406-415.

[7] R.W. Hayes, Creep deformation of Inconel 718 in the $650^{\circ} \mathrm{C}$ to $760^{\circ} \mathrm{C}$ temperature regime, Superalloy 718, 625, 706 and Various Derivatives (1991).

[8] W. Chen, M.C. Chaturvedi, DEPENDENCE OF CREEP FRACTURE OF INCONEL 718 ON GRAIN BOUNDARY PRECIPITATES, Acta Materialia 45(7) (1997) 2735-2746.

[9] X. Wang, X. Gong, K. Chou, Review on powder-bed laser additive manufacturing of Inconel 718 parts, Proceedings of the Institution of Mechanical Engineers, Part B: Journal of Engineering Manufacture 231(11) (2017) 1890-1903.

[10] H. Qi, M. Azer, A. Ritter, Studies of Standard Heat Treatment Effects on Microstructure and Mechanical Properties of Laser Net Shape Manufactured INCONEL 718, Metall and Mat Trans A 40(10) (2009) 2410-2422.

[11] I. Gibson, D.W. Rosen, B. Stucker, Additive Manufacturing Technologies: Rapid Prototyping to Direct Digital Manufacturing, Springer, New York, 2010.

[12] F. Wang, Mechanical property study on rapid additive layer manufacture Hastelloy ${ }^{\circledR} X$ alloy by selective laser melting technology, The International Journal of Advanced Manufacturing Technology 58(5) (2011) 545-551.

[13] Q. Jia, D. Gu, Selective laser melting additive manufacturing of Inconel 718 superalloy parts: Densification, microstructure and properties, Journal of Alloys and Compounds 585(0) (2014) 713-721.

[14] K.N. Amato, S.M. Gaytan, L.E. Murr, E. Martinez, P.W. Shindo, J. Hernandez, S. Collins, F. Medina, Microstructures and mechanical behavior of Inconel 718 fabricated by selective laser melting, Acta Materialia 60(5) (2012) 2229-2239.

[15] M. Pröbstle, S. Neumeier, J. Hopfenmüller, L.P. Freund, T. Niendorf, D. Schwarze, M. Göken, Superior creep strength of a nickel-based superalloy produced by selective laser melting, Materials Science and Engineering: A 674 (2016) 299-307. 
[16] Z. Wang, K. Guan, M. Gao, X. Li, X. Chen, X. Zeng, The microstructure and mechanical properties of deposited-IN718 by selective laser melting, Journal of Alloys and Compounds 513(0) (2012) 518-523.

[17] D. Zhang, W. Niu, X. Cao, Z. Liu, Effect of standard heat treatment on the microstructure and mechanical properties of selective laser melting manufactured Inconel 718 superalloy, Materials Science and Engineering: A 644 (2015) pp. 32-40.

[18] Y.-L. Kuo, T. Nagahari, K. Kakehi, The Effect of Post-Processes on the Microstructure and Creep Properties of Alloy718 Built Up by Selective Laser Melting, Materials 11(6) (2018) 996.

[19] S. Tammas-Williams, P.J. Withers, I. Todd, P.B. Prangnell, The Effectiveness of Hot Isostatic Pressing for Closing Porosity in Titanium Parts Manufactured by Selective Electron Beam Melting, Metall and Mat Trans A 47(5) (2016) 1939-1946.

[20] W. Tillmann, C. Schaak, J. Nellesen, M. Schaper, M.E. Aydinöz, K.P. Hoyer, Hot isostatic pressing of IN718 components manufactured by selective laser melting, Additive Manufacturing 13 (2017) 93-102.

[21] A. Kreitcberg, V. Brailovski, S. Turenne, Effect of heat treatment and hot isostatic pressing on the microstructure and mechanical properties of Inconel 625 alloy processed by laser powder bed fusion, Materials Science and Engineering: A 689 (2017) 1-10.

[22] Z. Xu, C.J. Hyde, C. Tuck, A.T. Clare, Creep behaviour of inconel 718 processed by laser powder bed fusion, Journal of Materials Processing Technology 256 (2018) 13-24.

[23] B.S.M. Ali, T.H. Hyde, W. Sun, Small Two-Bar Specimen Creep Testing of Grade P91 Steel at $650^{\circ} \mathrm{C}$, High Temperature Materials and Processes 35(3) (2015) 243-252.

[24] T.H. Hyde, B.S.M. Ali, W. Sun, Analysis and Design of a Small, Two-Bar Creep Test Specimen, Journal of Engineering Materials and Technology 135(4) (2013) 041006-041006.

[25] S. International, Nickel Alloy, Corrosion and Heat-Resistant, Investment Castings, $52.5 \mathrm{Ni}$ - $19 \mathrm{Cr}-3.0 \mathrm{Mo}-5.1 \mathrm{Cb}(\mathrm{Nb})-0.90 \mathrm{Ti}-0.60 \mathrm{Al}-18 \mathrm{Fe}$, Vacuum Melted Homogenization and Solution Heat Treated, SAE International, 2012.

[26] G. Petzow, Metallographic etching : techniques for metallography, ceramography, plastography, 2nd ed., ASM International Materials Park, Ohio, 1999.

[27] A.F. Liu, Mechanics and Mechanisms of Fracture: An Introduction, ASM International2005.

[28] M. Kuna, Classification of Fracture Processes, in: M. Kuna (Ed.), Finite Elements in Fracture Mechanics: Theory - Numerics - Applications, Springer Netherlands, Dordrecht, 2013, pp. 13-20.

[29] M.L. Martin, J.A. Fenske, G.S. Liu, P. Sofronis, I.M. Robertson, On the formation and nature of quasi-cleavage fracture surfaces in hydrogen embrittled steels, Acta Materialia 59(4) (2011) 1601-1606.

[30] G. Chen, Q. Wang, F. Liu, Z. Wang, J. Dong, X. Xie, Microstructure and Properties of Fine Grain IN718 Alloy Bar Products Produced by Continuous Rolling, Superalloy 718 and Derivatives, John Wiley \& Sons, Inc.2010, pp. 971-981.

[31] M.E. Kassner, Fundamentals of Creep in Metals and Alloys, Elsevier Science2015.

[32] S. Xu, A.K. Koul, J.I. Dickson, Creep crack growth in the absence of grain boundary precipitates in UDIMET 520, Metall and Mat Trans A 32(13) (2001) 795-804.

[33] M. Chaturvedi, Y. Han, Creep deformation of Alloy 718, Superalloys 718 (1989) 489-498.

[34] S. Azadian, L.-Y. Wei, R. Warren, Delta phase precipitation in Inconel 718, Materials Characterization 53(1) (2004) 7-16. 
[35] S. Azadian, Aspects of Precipitation in the Alloy Inconel 718, Department of Applied Physics and Mechanical Engineering, Luleå University of Technology 2004.

[36] W.-D. Cao, Solidification and solid state phase transformation of Allvac ${ }^{\circledR}$ 718PLUS ${ }^{\text {TM }}$ alloy, Superalloys 718, 625, 706 and Derivatives (2005) 165-177. 